Akbar_et_al-2016-Letters_in_Applied_Microbiology.pdf

\title{
Efficacy of different caffeine concentrations on growth and ochratoxin A production by Aspergillus species
}

\author{
A. Akbar, A. Medina \& N. Magan \\ Applied Mycology Group, AgriFood Theme, Cranfield University, Cranfield, Beds. MK43 \\ OAL, U.K.
}

Corresponding author: Prof. N. Magan, Applied Mycology Group, AgriFood Institute, Cranfield University, Cranfield, Beds. MK43 0AL, U.K. Tel: +44 1234758308

\section{E.mail: n.magan@cranfield.ac.uk}

Running title: Caffeine inhibition of growth and toxin production

Significance and impact of the study: Arabic (0.6\%) and Robusta coffee (4\%) have significantly different amounts of endogenous caffeine. The growth of six ochratoxigenic fungi which contaminate coffee with ochratoxin A (OTA) had differential tolerance/sensitivity to concentrations of caffeine in vitro in this range. However, low concentrations of caffeine $(<0.5 \%)$ was inhibitory to OTA production. These results are discussed in the context of the potential for using such information for the design of minimisation strategies to control mycotoxin production in such products.

\begin{abstract}
The objective of this study was to evaluate the effect of different caffeine concentrations (0$4 \%$ ) on (a) lag phase prior to growth, (b) growth rates, and (c) ochratoxin A (OTA) production by strains from the Aspergillus sections Circumdati and Section Nigri groups, isolated from coffee, when grown on a conducive medium at 0.98 water activity and $30^{\circ} \mathrm{C}$. The lag phases prior to growth increased with caffeine concentration. A strain of A. niger and A. carbonarius were the most sensitive to caffeine with growth being inhibited by $<1 \%$ caffeine. For strains of $A$. westerdijkiae, A. ochraceus and A. steynii, although growth was inhibited significantly, some growth (10-15\% of controls) occurred in $4 \%$ caffeine. OTA production was significantly inhibited by only $0.5 \%$ caffeine for strains of $A$. westerdijkiae, $A$. niger and $A$. carbonarius. For $A$. steynii at least $1.5 \%$ caffeine was required to inhibit OTA production. In contrast, for the strain of $A$. ochraceus there was a stimulation of OTA at 3\% with a reduction at $4 \%$ caffeine. These results are discussed in the context of the different concentrations of caffeine found in Arabica and Robusta coffee and the development of minimisation strategies.
\end{abstract}

Key words: Caffeine concentration, Aspergillus, lag phase, growth, ochratoxin A

\section{Introduction}

Caffeine (1,3,7-trimethylxanthine) has been shown to have an inhibitory effect on a number of mycotoxigenic Aspergillus and Penicillium species by reducing both growth and 
mycotoxin production such as aflatoxins, ochratoxin A, sterigmatocystin, patulin and citrinin (Buchanan et al. 1978; 1982; 1983; Nartowicz et al. 1979). The caffeine concentration endogenously present in coffee varies with the type of bean. Thus, Arabica coffee contains approx. 0.6\% caffeine, while Robusta coffee about 4\% (Oestreich-Janzen 2010). Therefore, the question arises as to whether caffeine concentration may influence the ability of ochratoxigenic fungi to colonise and produce ochratoxin A (OTA) in the presence of different concentrations of caffeine.

Some studies have suggested that caffeine plays a role in aflatoxin $\mathrm{B}_{1}$ inhibition in coffee (Nartowicz et al. 1979). However, Aspergillus flavus colonisation of coffee and aflatoxin $\mathrm{B}_{1}$ contamination is not as important as OTA contamination. Tsubouchi et al. (1985) reported inhibition of growth and OTA production by A. ochraceus IFM 0458 in a Yeast Extract Sucrose (YES) medium containing 1\% caffeine. In contrast, the production of OTA was found to be higher in the presence of 0.5 and $1.0 \%$ caffeine in another strain of $A$. ochraceus IFM S-235. However, there are few detailed studies which have attempted to examine the efficacy of different concentrations of caffeine on growth and mycotoxin production by a range of mycotoxigenic species which are responsible for OTA contamination of coffee. A few studies have also suggested that some Aspergillus strains (e.g. A. ochraceus, A. elegans and A. sclerotiorum) all isolated from green coffee beans and grown on ground coffee-based media could degrade caffeine (Tsubouchi et al. 1985).

The objectives of the present study was to examine the effect of different concentrations of caffeine (0-4\%) on (a) the lag phase prior to growth, (b) growth rates and (c) ochratoxin A (OTA) production by 6 strains from the Aspergillus section Nigri and Aspergillus section Circumdati on a conducive YES-based medium at $0.98 \mathrm{a}_{\mathrm{w}}$ and $30^{\circ} \mathrm{C}$. Species from these groups are responsible for contamination of coffee with OTA.

\section{Results and Discussion}

The effect of caffeine $(0.5-4 \%)$ on the lag phase $\left(\lambda\right.$, days), growth (mm day $\left.{ }^{-1}\right)$ and OTA production $\left(\mathrm{ng} \mathrm{g}^{-1}\right)$ of the different strains and species examined are shown in Figure 1a-1f.

This clearly shows that for all the strains examined, there was an increase in the lag phase as the caffeine concentration was increased. In terms of growth rate A. westerdijkiae (B2; 121986), were reduced by almost $60 \%$ with $0.5 \%$ caffeine and by $>90 \%$ in $4 \%$ caffeine concentration when compared to the untreated controls. However, for A. niger (A 1911) and A. carbonarius (ITAL 204) there was almost complete inhibition with $>0.5 \%$ caffeine concentration. For A. ochraceus (ITAL 14) there was a decrease in growth by about $50 \%$ and $94 \%$ in 0.5 and $4 \%$ caffeine respectively. In the case of $A$. steynii (CBS 112814), growth was inhibited by almost $70 \%$ in $0.5 \%$ caffeine and reduced by $>90 \%$ in $4 \%$ caffeine compared to control (see Figure 1).

In terms of OTA production, with the exception of A. steynii (CBS 112814) and A. ochraceus (ITAL 14), toxin production was completely inhibited by $0.5 \%$ caffeine. A. steynii (CBS 112814 ) was relatively tolerant to $0.5-1.0 \%$ caffeine with only a $24 \%$ reduction in OTA production. The only exception was A. ochraceus (ITAL 14) where OTA production was significantly increased in the presence of $2-4 \%$ caffeine. The highest OTA production by $A$. ochraceus (ITAL 14) reached $8.7 \mathrm{ng} \mathrm{g}^{-1}$ in $3 \%$ caffeine.

Statistically, the caffeine concentration had a significant effect $(p<0.05)$ on the lag phases prior to growth, growth and OTA production (see Table 1). This confirms the increase in lag phase for all strains with increasing caffeine concentration. The growth of all strains was significantly $(P<0.05)$ affected by caffeine concentration, with the highest growth in the 
control and the $0.5 \%$ concentration for all strains and this was reduced with increasing caffeine concentration. Statistical analysis showed that, overall, the mean OTA productions were variable among all strains. A similar effect on OTA production was found in the two strains at A. westerdijkiae (B 2, CBS 121986), where a large reduction in OTA production occurred in all the caffeine concentrations. The highest OTA production was found in $A$. carbonarius (ITAL 204) and A. steynii (CBS 112814) at $0.5 \%$ caffeine concentration. The stimulation of OTA production by the A. ochraceus strain in the presence of 2-3\% caffeine may be due to a combined stress response die to $a_{w} x$ inhibitory compound. Previously, intermediate concentrations of aliphatic acid based preservatives (calcium propionate, potassium sorbate) were shown to stimulate OTA production by Penicillium verrucosum. The was supported by molecular analysis of the otapksPV gene expression involved in OTA biosynthesis as well as phenotypic toxin production (Schmidt-Heydt et al. 2007).

No previous studies have examined the effect of different concentrations of caffeine on lag phases prior to growth, growth and OTA production by strains/species of the Aspergillus sections Circumdati and Nigri. This study has shown that increasing concentrations of caffeine had a significant impact on both growth and OTA production. Overall, for strains of A. niger (A 1911) and A. carbonarius (ITAL 204) there was inhibition of both growth and OTA production by $>1 \%$ caffeine concentration.

Overall, more Arabica (Coffea arabica) than Robusta (Coffea canephora) is consumed; with the former accounting for $75 \%$, and the latter, $25 \%$ of the total world-wide market. Robusta coffee beans have a more concentrated amount of caffeine reaching 4-5\% and is characterised by its bitterness, with less characteristic aroma compounds. Arabica coffee has more flavour and aroma and less than half the caffeine of Robusta beans (Kreicbergs et al. 2011). This could be important in terms of colonisation by ochratoxigenic fungi and OTA contamination in these two types of coffee beans. However, few studies have considered this aspect.

Previously, Buchanan et al. (1982) reported an inhibitory effect of caffeine on OTA biosynthesis and growth of $A$. ochraceus (= A. westerdijkiae based on the new classification; Abdel-Hadi and Magan 2009). This might be due to caffeine interfering with lipid accumulation. Some fungal species accumulate lipids, including A. flavus and A. ochraceus as a result of secondary metabolism (Gupta et al. 1970; Shin and Marth 1974). Previously, growth and OTA production by a strain of $A$. ochraceus was completely inhibited by caffeine at $1.0-2.0 \%$ on a YES medium after 3-21 days (Nehad et al. 2005). It may be possible that caffeine content affects the colonisation and production of OTA. Interestingly, A. steynii was more tolerant while A. ochraceus (ITAL 14) was stimulated to produce higher amounts of OTA at $>2 \%$ caffeine concentrations. Previously, caffeine concentrations of $1-2 \%$ were found to completely inhibit the growth and OTA production by A. ochraceus on a conducive YES medium over 3-21 days incubation (Nehad et al., 2005). It appears that a higher caffeine concentration actually inhibits growth and mycotoxin production by some mycotoxigenic species, although there may be some exceptions. This area needs more investigation to better understand the relationship between caffeine content of coffee, the contamination with mycotoxigenic fungi and the interactions at a molecular and physiological level.

\section{Material and methods}

\section{Fungal strains}

One strain of Aspergillus westerdijkiae (B 2) was isolated from green coffee beans imported from Ethiopia. A second strain of the same species (A. westerdijkiae; CBS 121986) was from the CBS Culture Collection as was the strain of A. steynii (CBS 112814). Both were isolated 
from coffee beans. These were kindly supplied by Dr. B. Patino (Complutense University, Madrid, Spain). A strain of Aspergillus niger (A 1911), was kindly provided by Prof. Paola Battilani (Università Cattolica del Sacro Cuore, Piacenza, Italy), and one each of $A$. carbonarius (ITAL 204) and A. ochraceus (ITAL 14), isolated from Arabica coffee beans in Brazil were kindly provided by Dr. Marta Taniwaki (ITAL, Campinas, Brazil).

Media

The basic YES medium was prepared with $20 \mathrm{~g}$ yeast extract (Oxoid, Basingstoke, Hampshire, UK) and agar (Technichal agar No. 2; Oxoid Ltd), Sucrose $150 \mathrm{~g}$ and $0.5 \mathrm{~g}$ $\mathrm{MgSO}_{4} \cdot 7 \mathrm{H}_{2} \mathrm{O}$. This was made up to a litre with a Universal buffer mixture by combining 63.15 $\mathrm{g}$ of $0.2 \mathrm{M} \mathrm{NA} 2 \mathrm{HPO} 4 \mathrm{ml}^{-1}$ and $36.85 \mathrm{~g}$ of $0.1 \mathrm{M}$ Citric acid ml$^{-1}$ (McIlvaine's buffer solutions) to obtain a $\mathrm{pH}$ value of 6.0 . The solution was modified with glycerol $(9.2 \mathrm{ml}$ per $100 \mathrm{ml} \mathrm{ml}$ medium) to obtain a water activity of 0.98 (Abdel-Hadi and Magan 2009). After autoclaving the medium at $121^{\circ} \mathrm{C}$ for $10 \mathrm{~min}$ the medium was allowed to cool to $45^{\circ} \mathrm{C}$. The caffeine concentrations (\%) (Sigma-Aldrich) were then added in the range $0.5-4 \%$ by addition to the molten cooled medium. This was then shaken well before pouring into $9 \mathrm{~cm}$ Petri plates (15$16 \mathrm{ml}$ per plate). After they had cooled and solidified they were stored in polyethylene bags at $4^{\circ} \mathrm{C}$ until used. Before use they were allowed to equilibrate at $25^{\circ} \mathrm{C}$ to prevent any condensation in the individual Petri plates.

\section{Inoculum preparation}

The inoculum was prepared by growing each strain on Malt Extract Agar (Oxoid Ltd, Basingstoke, Hampshire, U.K.) at $25^{\circ} \mathrm{C}$ for 7 days. Spore suspensions were prepared by agitating the colony surface with a sterile spatula in $9 \mathrm{~mL}$ of sterile distilled water containing $0.05 \%(\mathrm{w} / \mathrm{v})$ Tween 80 . The spore suspensions were standardised at $10^{6}$ spores $\mathrm{ml}^{-1}$ and the media were centrally inoculated with $7 \mu \mathrm{l}$ of the spore suspension. The treatments were incubated at $30^{\circ} \mathrm{C}$ for 9 days. The experiment was carried out with three replicates per treatment for each strain and repeated once.

\section{Calculation of lag phase prior to growth and growth rate}

The diameter of the colonies was measured in two directions at right angles to each other every day, until the colonies reached the Petri plate margin. The change in the colony radius (mm) vs time (days) for each strain was plotted in Microsoft Excel®. After data plotting, a linear model was used to calculate the relative growth rates $\left(\mathrm{mm} \mathrm{day}^{-1}\right)$ and the lag phases prior to growth initiation. The growth rates $\left(\mathrm{mm} \mathrm{day}^{-1}\right)$ were obtained as the slope of the line. By using the same equation, lag time (in days) were calculated by the regression line formula. The square of the linear correlation coefficients was $\geq 0.98$.

\section{Extraction, detection and quantification of OTA}

Five plugs ( $4 \mathrm{~mm}$ diameter) from three replicates were transferred after 9 days incubation at $30^{\circ} \mathrm{C}$ on YES medium to $2 \mathrm{ml}$ Eppendorf tubes and weighed. $750 \mu 1$ methanol was added to each Eppendorf tube. The samples were then shaken using a KS 501 digital orbital shaker for $30 \mathrm{~min}$ and centrifuged for $10 \mathrm{~min}$ at $15000 \mathrm{xg}$. The supernatant was filtered directly into HPLC vials.

The HPLC system used for OTA analysis was an Agilent 1200 Series system (Agilent, Berks, UK) with a fluorescence detector (FLD), an auto sampler, autosampler thermostat, thermostated column compartment, on-line degasser, and binary pump. Initial comparisons were performed in the isocratic mode. The mobile phase was AcN:water:acetic acid $(57: 41: 2$, 
$\mathrm{v} / \mathrm{v} / \mathrm{v})$ using a flow rate of $1 \mathrm{ml} \mathrm{min}^{-1}$. Separation was performed using an Agilent Poroshell 120 EC-C18 $4.6 \mathrm{~mm} \times 100 \mathrm{~mm}, 2.7 \mathrm{~m}$ analytical column. The column was preceded by the appropriate pre-column. FLD detection was performed using $\lambda_{\mathrm{exc}} 333 \mathrm{~nm}$ and $\lambda_{\mathrm{em}} 460$ ((excitation and emission wavelengths, respectively) for $12 \mathrm{mins}$. The injection volume was set at $20 \mu \mathrm{l}$. After analysis the signals were processed using Agilent ChemStation software Ver. B Rev: 03.01 [317] (Agilent Technologies, Palo Alto, CA, USA). Ochratoxin A standard containing $1.0 \mathrm{mg} \mathrm{ml}^{-1}$ in methanol was purchased from Sigma (Sigma-Aldrich, UK). The Limit of Detection and Limit of Quantification were $0.09 \mathrm{ng} \mathrm{g}^{-1}$ and $0.32 \mathrm{ng} \mathrm{g}^{-1}$, respectively.

This method has been detailed in Sultan et al. (2014).

\section{Data analysis}

A full factorial design with different caffeine concentrations was carried out in triplicate, and repeated once, for calculating the lag phases (prior to growth) and the relative growth rates. Normality was checked using the Kolmogorov-smirnov test. Analysis of data, the effects of $\mathrm{a}_{\mathrm{w}}$, temperature and their interaction were examined by the Kruskal-Wallis (non-parametric) where data was not normally distributed. For normally distributed data the data sets were analysed using Minitab® 16 package (Minitab Inc., 2010. State College, PA, USA). The statistically significant level was set at $P<0.05$ for all single and interacting treatments.

\section{Acknowledgements}

Mrs A. Akbar is very grateful to the Kuwaiti Government for a PhD scholarship. We are also very grateful to Dr. B. Patino, Prof. Paola Battilani and Dr. Marta Taniwaki for providing the strains used in this study.

\section{Conflict of interest}

The authors of this work declare that there is not conflict of interest.

\section{References}

Abdel-Hadi, A. and Magan, N. (2009) Influence of environmental factors on growth, sporulation and ochratoxin A and B production of the new grouping of the A. ochraceus group. World Mycotox J 2, 429-434.

Buchanan, R. L., and Fletcher, A.M. (1978) Methylxanthine inhibition of aflatoxin production. J Food Sci 43, 654-655.

Buchanan, R. L., Tice, G. and Marino, D. (1982) Caffeine inhibition of ochratoxin A production. J Food Sci 47, 319-321.

Buchanan, R. L., Harry, M.A. and Gealt, M.A. (1983) Caffeine inhibition of sterigmatocystin, citrinin and patulin production. J Food Sci 48, 1226-1228.

Gupta, S. R., Viswanathan, L. and Venkitasubramanian, T.A. (1970) A comparative study of lipids of a toxigenic and a nontoxigenic strain of Aspergillus flavus. Indian J Biochem 7,108-111.

Kreicbergs, V., Dimins, F., Mikelsone, V. and Cinkmanis, I. (2011) Biologically active compounds in roasted coffee. Conference Proceedings of the 6th Baltic Conference on Food Science and Technology "Innovations for Food Science and Production", FOODBALT, pp. 110-115. ISSN 2255-9817 (online).

Nartowicz, V., Buchanan, R.L., Segall, S. (1979). Aflatoxin production in regular and decaffeinated coffee beans. J Food Sci 44, 446-448. 
Nehad, E. A., Farag, M. M., Kawther, M. S., Abdel-Samed, A. K. M., Naguib, K. (2005). Stability of ochratoxin A (OTA) during processing and decaffeination in commercial roasted coffee beans. Food Addit Contam 22, 761-767.

Oestreich-Janzen, S. (2010). Chemistry of Coffee. In L. Mander \& H. W. Liu (Eds.). Comp Nat Pro II Chem and Bio 3, 1085-1117.

Schmidt-Heydt, M. Baxter, E.S., Geisen, R., Magan, N. (2007) Physiological relationship between food preservatives, environmental factors, ochratoxin and otapks $\mathrm{Pv}$ gene expression by Penicillium verrucosum. Int J Food Microbiol 119, 277-283.

Shin, C. N. and Marth, E. H. (1974). Aflatoxin formation, lipid synthesis, and glucose metabolism by Aspergillus parasiticus during incubation with and without agitation. Biochem Biophys Res Commun 50, 237.

Sultan, Y., Magan, N., and Medina, A. (2014) Comparison of five different $\mathrm{C}_{18}$ HPLC analytical columns for the analysis of ochratoxin A in different matrices. J Chromat B, 971, 89-93.

Tsubouchi H, Terada H, Yamamoto K, Hisada K, Sakabe Y. (1985). Caffeine degradation and increased ochratoxin A production by toxigenic strains of Aspergillus ochraceus isolated from green coffee beans. Mycopathologia 90, 181-186. 
Table 1: Summary statistical table for the Lag phase ( $\lambda$, days), growth rate and OTA production of 6 strains on caffeine concentration by using Kruskal-Wallis Test (nonnormality data) and ANOVA (normality data).

\section{Factors}

\begin{tabular}{|c|c|c|}
\hline Strains & $\begin{array}{l}\text { Caffeine } \\
\text { concentration }(\%)\end{array}$ & Response \\
\hline \multirow{3}{*}{ A. westerdijkiae (B 2) } & $\mathbf{S}^{\mathbf{b}}$ & Lag time $(\lambda$, days $)$ \\
\hline & $\mathbf{S}^{\mathbf{a}}$ & Growth rate $\left(\mathrm{mm} \mathrm{day}^{-1}\right)$ \\
\hline & $\mathbf{S}^{\mathbf{a}}$ & OTA $\left(\operatorname{ng~g}^{-1}\right)$ \\
\hline \multirow{3}{*}{$\begin{array}{l}\text { A. westerdijkiae } \\
\text { (CBS 121986) }\end{array}$} & $\mathbf{S}^{\mathbf{b}}$ & Growth rate $\left(\mathrm{mm} \mathrm{day}^{-1}\right)$ \\
\hline & $\mathbf{S}^{\mathbf{a}}$ & Lag phase $(\lambda$, days $)$ \\
\hline & $\mathbf{S}^{\mathbf{a}}$ & OTA $\left(\operatorname{ng~g}^{-1}\right)$ \\
\hline \multirow{3}{*}{ A. niger (A 1911) } & $\mathbf{S}^{\mathbf{a}}$ & Growth rate $\left(\mathrm{mm} \mathrm{day}^{-1}\right)$ \\
\hline & $\mathbf{S}^{\mathbf{a}}$ & Lag phase ( $\lambda$ days $)$ \\
\hline & $\mathbf{S}^{\mathbf{a}}$ & OTA $\left(n g^{-1}\right)$ \\
\hline \multirow{3}{*}{ A. carbonarius (ITAL 204) } & $\mathbf{S}^{\mathbf{a}}$ & Growth rate $\left(\mathrm{mm} \mathrm{day}^{-1}\right)$ \\
\hline & $\mathbf{S}^{\mathbf{a}}$ & Lag phase $(\lambda$, days $)$ \\
\hline & $\mathbf{S}^{\mathbf{a}}$ & OTA $\left(\operatorname{ng~g}^{-1}\right)$ \\
\hline \multirow{3}{*}{ A. ochraceus (ITAL 14) } & $\mathbf{S}^{\mathbf{a}}$ & Growth rate $\left(\mathrm{mm} \mathrm{day}^{-1}\right)$ \\
\hline & $\mathbf{S}^{\mathbf{a}}$ & Lag phase $(\lambda$, days $)$ \\
\hline & $\mathbf{S}^{\mathbf{a}}$ & OTA $\left(\operatorname{ng~g}^{-1}\right)$ \\
\hline \multirow{3}{*}{ A. steynii (CBS 112814) } & $\mathbf{S}^{\mathbf{a}}$ & Growth rate $\left(\mathrm{mm} \mathrm{day}^{-1}\right)$ \\
\hline & $\mathbf{S}^{\mathbf{a}}$ & Lag phase $(\lambda$, days $)$ \\
\hline & $\mathbf{S}^{\mathbf{a}}$ & OTA $\left(n g g^{-1}\right)$ \\
\hline
\end{tabular}

$P$ values of 0.05 or less are often considered evidence that there is at least one significant effect in the model.

S Significant

${ }^{\text {a }}$ Kruskal-Wallis test.

${ }^{\mathrm{b}}$ ANOVA. 
(a) A. westerdijkiae (B 2)

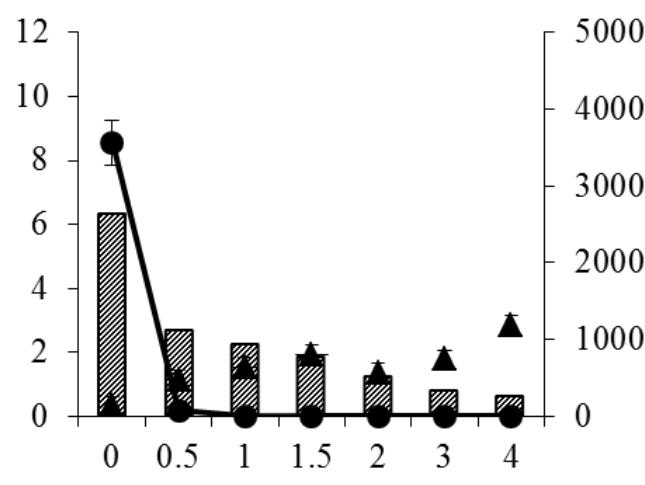

(c) A. niger (A 1911)

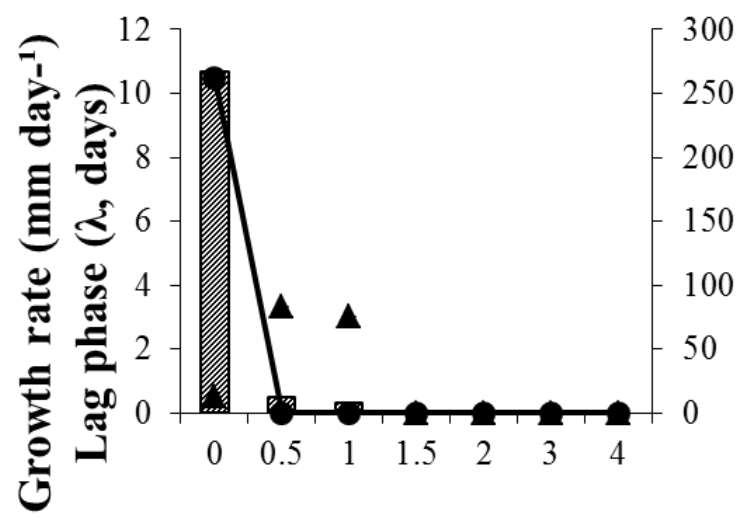

(e) A. ochraceus (ITAL 14)

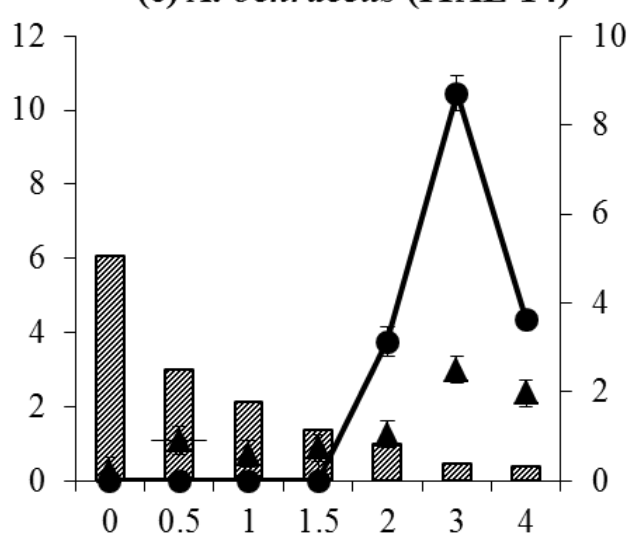

(b) A. westerdijkiae (CBS 121986)

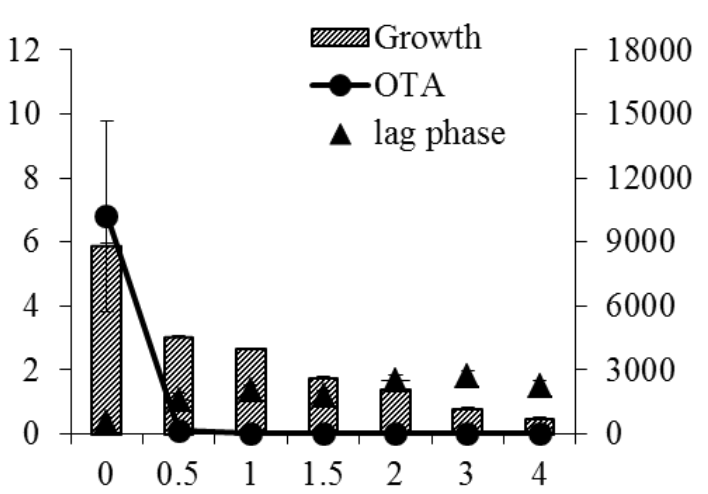

(d) A. carbonarius (ITAL 204)

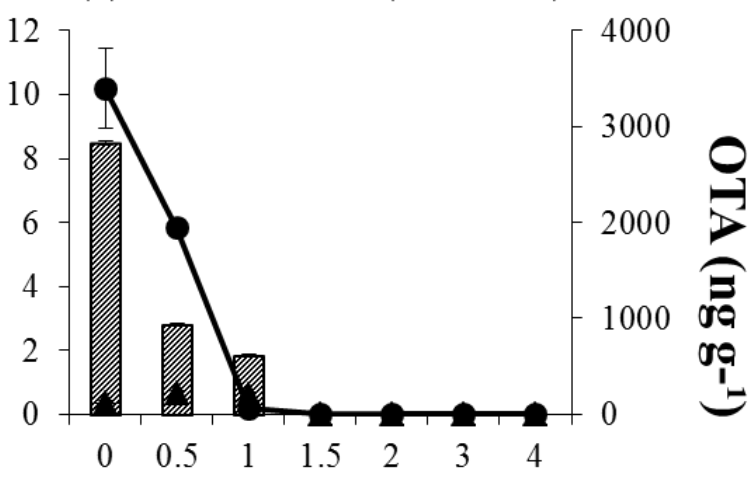

(f) A. steynii (CBS 112814)

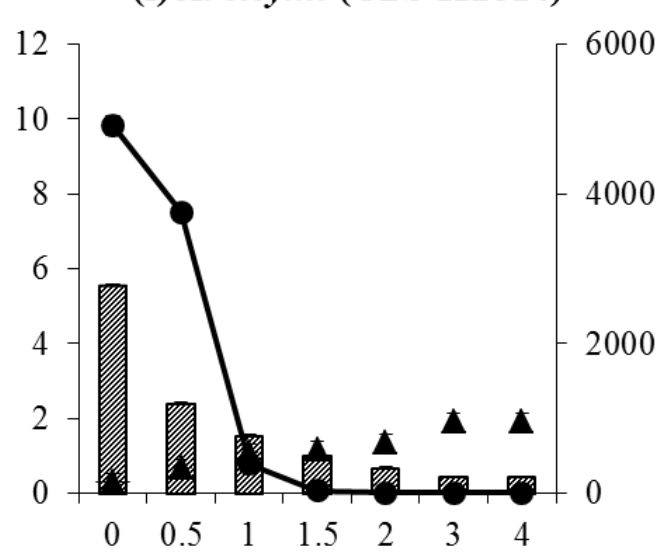

\section{Caffeine concentration (\%)}

Figure 1 Effect of caffeine concentration (0.5-4\%) on lag phase ( $\lambda$, days), growth and ochratoxin a (OTA) production by (a) and (b) two strains of A. westerdijkiae (B2, CBS 121986), (c) A. niger (A 1911), (d) A. carbonarius (ITAL 204), (e) A. steynii (CBS 112814) and (f) A. ochraceus (ITAL 14) on a $0.98 \mathrm{a}_{\mathrm{w}}$ YES medium at $30^{\circ} \mathrm{C}$ for 9 days. Bars indicate standard error of the mean. 